\title{
Research on the Lung Cancer in China and the Possible Solutions
}

\author{
$\mathrm{Yu} \mathrm{Xia}{ }^{1, *}$ \\ ${ }^{1}$ Dwight-Englewood School, New Jersey, 07631, U.S. \\ *Corresponding author. Email: yxia23@d-e.org

\begin{abstract}
Tobacco smoking and air pollution are two public health concerns all over the world and they are also the cause of chronic obstructive pulmonary disease. In order to lower the smoking attribute cancer mortality rate, China has implemented several smoking bans since the 1990s. To analyze the effectiveness of the smoking ban in China from the research data done by the previous scientists, smoking bans and actions from other countries will be used. The smoking ban in China is useful in some way but still has to be improvised. This paper is to present the laws implemented by the Chinese government and the government of other countries and to compare their effectiveness.
\end{abstract}

Keywords: Lung Cancer, Smoking, Smoking Ban, Air Pollution

\section{INTRODUCTION}

Lung cancer is a multi-step and multi-factorial disease, it is currently the malignant tumor with the highest mortality rate and the third-highest morbidity rate in the world and smoking is one of the risk factors. The epidemiologists nowadays not only study the smoking bans made by the governments in different countries and the effectiveness of each law but also research on the victims of smoking and air pollution that finally led to lung cancer. However, the epidemiologist hasn't tried each of the smoking bans in different countries yet. By doing so, they are able to know what the ban should be like for each country and what they should improvise on the smoking bans to make the most effective in each country. The government is able to get rid of the ineffective policies on smoking and design ones that benefit the country the most. With all these changes, people can live in the less polluted environments.

\section{THE CONSEQUENCE OF SMOKING IN CHINA}

Cancer is also the malignant tumor with the highest morbidity and mortality rate in China since China is the largest consumer of tobacco in the world. The incidence and mortality of lung cancer in China are much higher than the world average and smoking is one of the leading risk factors. In China, lung cancer incidence in both men and women has increased rapidly in recent years, imposing a great threat to human health. Based on the "Report of cancer incidence and mortality in China" by Chin J Oncol [1], among the data collected from 339 cancer registries, the ASIR of lung cancer was 36.71 per 100000 . The rates in men and women were 49.94 per 100000 and 23.89 per 100000 , respectively. The number of new cases in urban areas was 457000 , which is 1.4 times higher than that in rural areas. "The numbers of smoking-attributable cancer deaths increased from 2484 in 2005 to 2999 in 2010 and 4148 in 2015, with corresponding PAFs of $26.41 \%, 25.76 \%$ and $29.13 \%$, respectively. The PAFs were higher among men (vs. women) for all cancers except cervical cancer. In 2005, lung, liver, esophageal and stomach cancers were most frequently associated with smoking-associated cancer mortality, and lung cancer had the greatest PAF, followed by nasopharyngeal, oral and esophageal cancers." [2]. In 2015 , about a third of cancer deaths in men and the fifth death in women were attributable to smoking, and most of these were caused by liver, stomach, and lung cancer. Over time, a downward trend in smoking-attributable deaths was observed among people younger than 50 years. The ASIR is similar in both urban and rural areas, however men have double the ASIR as women. As a result, identifying the frequency and the pattern of health event of people with lung cancer is critical to provide background knowledge for cancer prevention and control, and, hopefully, to reduce the incidence and mortality of the disease. 


\section{SMOKING BAN}

China started to implement prohibiting smoking in public in the 1970s but the ban on smoking tobacco control is not as strict as other countries. For example, Bhutan became the first smoke-free country in 2010 due to the Tobacco Control Act. For foreign smokers who enter Bhutan, they must pay a high price if they want to smoke. After paying a $200 \%$ tariff, they can bring tobacco into the country, and still they are allowed to smoke only when they follow the basic rule which is "not affecting other people." In addition, smoking rates in China began to rise rapidly in the 1980 s, and by 2015 , there were more than 300 million smokers, compared to America, which has implemented various tobacco control measures for about 30 years and has effectively reduced the smoking rate of adults and the incidence of lung cancer. The Minister of Health's main goal in 2011 was: "by the year 2010, all health administration offices, both military and non-military, and at least $50 \%$ of all medical and health institutions should become smokefree units, so that the goal of a total smoking ban in all health administration offices and medical and health institutions can be fulfilled by 2011.'[3]. However, the smoking law they implement bans smoking in 12 types of public places including indoor smoking at schools, hospitals, sport stadiums, public transport vehicles and Internet cafes. Anyone caught smoking would first be given a warning and then face a fine of 50 to 200 yuan if they resist. And according to the data on the mortality rate of lung cancer, it is obvious that the policy has almost no effect on banning smoking and diminishing the number of people getting lung cancer each year. Even if smoking is banned in the public, those tobacco smokers can still smoke at home, and their families will become the passive smokers, causing the mortality rate of lung cancer to increase. This issue is related to public health because by solving this issue, policy-making and science of improving the health of the community which is the principles of public health, are required. In order to effectively decline the incidence of lung cancer in China, stricter policies should be published. Some ways that this issue can be resolved is: First, the government should implement real name purchase of cigarettes, anyone who has been fined for smoking indoors isn't allowed to purchase cigarettes anymore. If people keep on smoking indoor even after being fined, they will be sent to the jail after being reported. Even though some people being fined still secretly purchase the tobacco illegally, such as from the black market, the chances of people getting lung cancer from smoking may still decrease. Secondly, the government should raise the tax collected for tobacco and find alternatives for tobacco products. By raising the tax, fewer people will be willing to purchase tobaccos and there will be fewer people who become the victims of passive smoking. Other than raising the tax, the government can also print the picture of the corpses or the organs of the smokers on the cigarette case just like what the Indian government did, this can hopefully let people acknowledge the outcome of continuous smoking. By carrying out the plan, the number of people with lung cancer will be decreased significantly, the average lifespan will increase, and these new smoking ban policies will not only benefit the nicotine but also the victims of passive smoking. However, whether limiting the production of tobacco is the best solution is still being considered because there is many people who work in the tobacco industry and all their incomes depend on producing tobaccos. If the production line of tobacco is being suspended, many of them will lose their job and have to rely on the alms distributed by the government.

\section{AIR POLLUTION}

Although smoking is the predominant risk factor of lung cancer, air pollution is also a leading risk factor of this disease by making living near the factories or tobacco smokers the victims of passive smoking. Due to urbanization and industrialization in modern society, the polluted air has become a side effect to people's health all over the world, but especially in China. In China, it is very common to see women being exposed to secondhand smoking. The percentage of females over 15 years old who are exposed to secondhand smoking is $71.6 \%$ and $41.7 \%$ of women are exposed to second hand smoking every day. Women are more likely to be exposed to second-hand smoke at home public places, workplaces and homes are the main places of secondhand smoke exposure in China. According to reports, among Chinese women of childbearing age, nearly $2 / 3$ are at home and $>1 / 2$ are often exposed to second-hand smoke in the workplace. Female smokers have a higher risk of COPD than men. Smoking and second-hand smoke exposure can also increase the risk of breast cancer, cervical cancer and other diseases in women. Smoking and second-hand smoke exposure can also lead to an increase in female mortality, which is 1.33 times higher than that of non-smokers. Exposure of tobacco to pregnant women not only causes lung cancer but can also cause dystocia, miscarriage, premature delivery, stillbirth, or ectopic pregnancy, and severely affect all stages of fetal development, cause fetal growth retardation, congenital malformations, cause sudden infant death, low birth weight, and affect their intelligence and development. According to the Ministry of Ecology and Environment of the People's Republic of China's report on the air quality statistics in 338 urban areas, the air quality in $239(70.7 \%)$ areas had reached a hazardous level. This level of air quality, being confirmed by environmentalists, can affect people's health seriously. According to the report, "Fine particulate matter (PM) with a diameter of $<2.5 \mu \mathrm{m}$ suspended in the atmosphere is the chief component of atmospheric pollution. A PM2.5 level can result in the stimulation of factors that can seriously interfere with gas exchange. Long-term exposure to high level PM2.5 could increase the risk of 
lung cancer. $\mathrm{Fu}$ et al. found a positive association between PM2.5 and mortality, with R-values of 0.464 . Smokers seem to be more vulnerable. An American report clarified the correlation between exposure to ambient PM2.5 and life expectancy. For each $10 \mu \mathrm{g} / \mathrm{m}$ decrease in the concentration of fine PM2.5, life expectancy increases approximately $0.61 \pm 0.20$ /year." [4]. Thus, coming up with a plan to ameliorate the air quality is necessary and urgent. Although in China there is a manufacturing zone in each city to prevent the factories to be in areas too close to the city center, there are still many factories that disobey the environmental regulation on manufacturing. The Air Pollution Action Plan released in September 2013 became China's most influential environmental policy, the government also installed equipment to remove particulate matter, flue gas desulfurization, and denitrification, replaced coal with natural gas, and expanded clean energy vehicles. Even though these acts have significantly improved the air quality in most areas, more actions still are required to be taken to stop the illegal factories that disobey the law from producing air pollution. The government should establish a group of prosecutors who focuses on making sure that the factories are following the Air Pollution Action Plan and are not overload operating, emitting the amount of air that is more than the amount being set by the law. The Clean Air Act implemented by the United States government is a great example of a law that ameliorate the air quality and American health problem in the United States. According to U.S. Environmental Protection Agency, "Actions to control emissions from vehicles, factories, electric power plants, and more have reduced emissions of the most prominent pollutantsparticulate matter, sulfur oxides, nitrogen oxides, carbon monoxide, volatile organic compounds, and lead-by $73 \%$, even while the U.S. gross domestic product has grown by more than 250\%." [5]. Air in the United States is much healthier to breathe today than it was five decades ago, and this progress has been achieved, it appears, without detracting from the health of the U.S. economy. The U.S. Congress has periodically revisited the Clean Air Act and refined its ability to achieve clean air, but overall, the Act has worked very well. According to the research done by LinXiao, "From 2010 to 2015, secondhand smoke exposure among nonsmokers decreased in restaurants, government buildings, health-care facilities, schools, and public transportation in China $(\mathrm{p}<0.05)$. The relative change was most significant for schools $(52.1 \%)$, followed by public transportation (49.4\%) and government buildings (42.2\%). The percentage of secondhand smoke exposure reported in workplaces declined from $55.2 \%$ to $45.3 \%$. Secondhand smoke exposure at home reduced from $58.3 \%$ to $46.7 \%$. People's awareness that secondhand smoke could cause heart disease in adults, lung illness in children, and lung cancer in adults increased from $24.6 \%$ to $36.0 \%$." [6]. Although people affected by secondhand smoke in China have declined from 2010 to 2015, it is still a serious problem to be solved by the people who work in public health. By learning from the laws of other countries on air pollution, China can more effectively reduce the possibility of having lung cancer and the air quality will gradually improve.

\section{CONCLUSION}

This research paper still has many things to improve and revise because the solutions suggested in the paper still has to be tested if they can effectively decline the mortality rate of lung cancer in China. All the smoking bans and clean air acts that are effective and being used in other countries should be tested in China to see if they are also effective in China because sometimes these bans only work under a certain scenario. Without experimenting with these suggested solutions in real-life scenarios, it will be unclear if people would accept such laws and if there are any bugs in the solutions. For example, even if the tobaccos become real name purchased, it is still possible that those tobaccos smokers will purchase fake identities cards online or they might also purchase cigarettes on the black market, which is also against the laws. Also, banning tobacco completely might affect the economy of the tobacco industry. There is a large percentage of people in China who produce tobacco and all their income depends on tobacco dealing. If the tobacco industry become illegal, then numerous families will have no income and that will be a tremendous strike to them. By testing these solutions repeatedly and revising them, the mortality rate of lung cancer will eventually decline. Therefore, the future research and experiment should find the most effective way to decrease the smoking rate but also shouldn't be harmful to the working class.

\section{ACKNOWLEDGMENTS}

I've received numerous help throughout the writing of this paper. Professor Trochim has given me a lot of suggestions on the content and the topic of my paper. I've gained a lot of knowledge in his lessons and that information also helped me a lot during the writing.

\section{REFERENCES}

[1] Cao M, Chen W. Epidemiology of lung cancer in China. Thorac Cancer. 2019 Jan;10(1):3-7. doi: 10.1111/1759-7714.12916. Epub 2018 Nov 28. PMID: 30485694; PMCID: PMC6312841.

[2] Xu Z, Qi F, Wang Y, Jia X, Lin P, Geng M, Wang R, $\mathrm{Li}$ S. Cancer mortality attributable to cigarette smoking in 2005, 2010 and 2015 in Qingdao, China. PLoS One. 2018 Sep 20;13(9):e0204221. doi: 10.1371/journal.pone.0204221. PMID: 30235293; PMCID: PMC6157816. 
[3] Centers for Disease Control and Prevention. (2015, March 19). Exposure to secondhand tobacco smoke and interventions among pregnant women in China: A systematic review. Centers for Disease Control and Prevention. Retrieved November 5, 2021, from https://www.cdc.gov/pcd/issues/2015/14_0377.htm.

[4] Xing, Yu-Fei et al. "The impact of PM2.5 on the human respiratory system." Journal of thoracic $\begin{array}{lllll}\text { disease } & \text { vol. } & 8,1 & \text { (2016): } & \text { E69-74. }\end{array}$ doi:10.3978/j.issn.2072-1439.2016.01.19

[5] Greenbaum DS. The Clean Air Act: Substantial Success and the Challenges Ahead. Ann Am Thorac Soc. 2018 Mar;15(3):296-297. doi: 10.1513/AnnalsATS.201710-763PS. PMID: 29262262.

[6] Xiao L, Jiang Y, Zhang J, Parascandola M. Secondhand Smoke Exposure among Nonsmokers in China. Asian Pac J Cancer Prev. 2020 Jul 1;21(S1):17-22.

doi: 10.31557/APJCP.2020.21.S1.17. PMID: 32649166. 